\title{
The Improvement of Total Rewards and Working Condition for Taekwondo Instructor in the Covid-19 Era
}

\author{
Hyunjun Ju' and Eileen Lee\# \\ ${ }^{1}$ University of Nebraska High School, Lincoln, NE, USA \\ \#Advisor
}

$\underline{\text { ABSTRACT }}$

This study aims to identify the impact of COVID-19 on the Taekwondo industry and its workers and find directions for the overall development of the Taekwondo industry and the improvement of the working conditions of workers. This study looked for differences and commonalities through comparative studies between the U. S. and Korea and conducted an in-depth interview and survey with taekwondo masters and instructors. As a result, Taekwondo instructors in the U.S. and Korea played high self-esteem roles, but they were experiencing extreme economic difficulties due to COVID-19. Difficulties across the industry led to layoffs of workers and worsening working conditions. Comparative studies have shown different problems between the U.S. and Korea caused by COVID-19. In the U.S., Taekwondo instructors' self-esteem has declined, and turnover has increased. On the other hand, Korean instructors maintained self-esteem but complained of difficulties due to overtime and additional work. Comparative studies show that both countries have improvements to learn from each other. Taekwondo instructors in the U.S. need to increase their self-esteem while providing instructors with a vision for long-term careers. Taekwondo instructors in Korea need clear job classification and overtime pay. In addition, the online Taekwondo training program and selfdevelopment program for instructors recently established in the U.S. need to be benchmarked and applied in Korea. This study will contribute to the overall development of the Taekwondo industry and improve the long-term vision and working conditions of instructors of both countries.

\section{Introduction}

\section{Economic and Social Values of Taekwondo}

Taekwondo, a traditional Korean martial art, originated from an ancient martial art called Taekkyeon in the 4th century. Since the 7th century, during Korea's frequent wars against China, the martial value of Taekkyeon has been recognized from army. Further, Teakkyeon became more organized and popularized for national defense. Since then, Taekkyeon has been handed down between the military and traditional martial artists. By the 1960s, Taekkyeon has renamed Taekwondo and was modernized for the purpose of health care and sports for the people. Taekwondo has become one of the top 10 brands representing Korea and a valuable asset contributing significantly to Korea's economy and society. As a result of continued popularization and globalization, Taekwondo was adopted as an official Olympic sport at the 2000 Sydney Olympics and maintained for 20 years. Since being selected as an official Olympic sport, Taekwondo quickly expanded globalization and more than 80 million taekwondo instructors and trainees from 206 countries were registered (Global Taekwondo Industry Research 2018). As of 2019, there are currently 10,078 taekwondo gyms in Korea (Korea Taekwondo Association 2020). Now, the number of taekwondo trainees exceeded 5.5 million in Korea (Kukkiwon 2019). After Korea, the U.S. is the country where Taekwondo has spread the most. 
The U.S. currently has 30,000 masters (25,000 American masters and 5,000 Korean masters), and the cumulative number of trainees has exceeded 4 million. (World Taekwondo Federation 2017). Given the size of the total population, the Taekwondo population of the U.S. is likely to surpass Korea soon.

As such, Taekwondo in Korea and the U.S. has a massive impact on the economy in the sports sector, given the number of instructors and trainees. The economic value of Taekwondo is not only related to direct taekwondo training but also various industries linked to Taekwondo. Taekwondo also has tremendous economic effects on sports matketing and tourism, including sales of taekwondo training goods and contents for foreign Taekwondo instructors and trainees (Song Gilseop 2004). Taekwondo also has important social significance. Taekwondo gyms are distributed by the community, and local children are the main customers. The local taekwondo gym plays its role not only for taekwondo training and sports purposes but also for mental health training such as meditation, filial piety and sense of duty etc. Also, Taekwondo has a positive effect on growing students into one desirable member of society. Taekwondo has expanded its role beyond physical training to moral development such as manners, honesty, tolerance, and discipline, and social expectations have expanded to improving mental health (Kim Setae 2007). These social values of Taekwondo are recognized overseas including the U.S. (Lee Heenyeong 2008). In addition, in the U. S., many states do not have programs during evening hours after school hours. So if parents are working together, they use Taekwondo as a night care facility for children. In response, taekwondo gym continue developing programs at the level of professional "after school" education facilities (Han Hyejin 2020).

\section{The necessity of research}

As previously explained, Taekwondo is a sport with high economic and social impact, and large-scale employees are involved in related industries. However, the entire taekwondo industry is suffering from the COVID-19 situation. The Taekwondo gym is operated by owners who called "Master" and employees who called "instructor". The master is responsible for the overall operation of the Taekwondo gym, and also he trains students with instructor. The master can be defined as instructor and administrator.

By looking at actual media articles and research data, it is easier to feel the crisis. Most of the gyms endure this COVID-19 situation amid economic difficulties. These industry-wide difficulties are putting more pressure on employees and they could not receive a reasonable price for their work or there was not enough compensation for their livelihood. According to recent articles, there are many stories of taekwondo gyms in crisis due to COVID-19. There are some gyms where the number of trainees has been halved and some masters working part-time at night to cover the rental fee of gym (Kim Hyunsoo 2020). So far, 15 percent of taekwondo gym in Kora have been closed due to COVID-19. Due to the closure of the Taekwondo gym, instructors have lost their jobs or are not receiving proper wages (Lim Seongho 2021).

According to a study, Taekwondo industry fell into the vicious cycle owing to COVID-19: a decrease in the number of gym trainees, an economic loss, a reduction of instructor, and insufficient support from the government and taekwondo associations (Park Sungeon et al. 2021). This phenomenon is also happening in the U.S. taekwondo industry. After President Trump declared a state of emergency on March 2020, Taekwondo gyms in all regions had to be forcibly closed. Since then, the situation has become so serious that less than 20 percent of the gym trainees have returned to the gym (Han Hyejin 2020). As such, the COVID-19 has a significant influence on the taekwondo industry and related people. Therefore, research is urgently needed to identify the difficulties of taekwondo instructors due to COVID-19 and find ways to improve their working condition. 


\section{Methods}

\section{An object of study}

The study was conducted in four Taekwondo gyms in the U.S. and Korea. The research was conducted on multiple gyms, including two in the U.S. and two in Korea to obtain objective information. Interviews and surveys were conducted on four masters and eight instructors. The masters were all male and operated the gym for more than five years. The instructors were only selected more than a year of experience for the quality of the interview.

Table 1. Interviewees and survey participants' information

\begin{tabular}{|l|l|l|l|l|}
\hline Interviewee & Instructor Experience & Age & Gender & Country / Birth \\
\hline Master1 & $10 \mathrm{yr}+$ & $50 \mathrm{~s}$ & Male & US / Korea \\
\hline Master2 & $10 \mathrm{yr}+$ & $40 \mathrm{~s}$ & Male & US / Korea \\
\hline Master3 & $10 \mathrm{yr}+$ & $40 \mathrm{~s}$ & Male & Korea / Korea \\
\hline Master4 & $10 \mathrm{yr}+$ & $40 \mathrm{~s}$ & Male & Korea / Korea \\
\hline Instructor1 & $10 \mathrm{yr} \sim 5 \mathrm{yr}$ & $30 \mathrm{~s}$ & Male & US / Korea \\
\hline Instructor2 & $5 \mathrm{yr} \sim 3 \mathrm{yr}$ & $30 \mathrm{~s}$ & Male & US / Korea \\
\hline Instructor3 & Under $3 \mathrm{yr}$ & $20 \mathrm{~s}$ & Male & US / US \\
\hline Instructor4 & Under $3 \mathrm{yr}$ & $20 \mathrm{~s}$ & Male & US / Mexico \\
\hline Instructor5 & $5 \mathrm{yr} \sim 3 \mathrm{yr}$ & $30 \mathrm{~s}$ & Male & Korea / Korea \\
\hline Instructor6 & $\mathrm{Under} \mathrm{3yr}$ & $20 \mathrm{~s}$ & Female & Korea / Korea \\
\hline Instructor7 & $10 \mathrm{yr} ~ 5 \mathrm{yr}$ & $30 \mathrm{~s}$ & Male & Korea / Korea \\
\hline Instructor8 & $5 \mathrm{yr} \sim 3 \mathrm{yr}$ & $20 \mathrm{~s}$ & Male & Korea / Korea \\
\hline
\end{tabular}

\section{Research Tools}

This study used both qualitative and quantitative analyses to compensate for the lack of interviewees. The qualitative research method vividly listened to the situation of masters and instructors were experiencing through in-depth interviews and supplemented and improved the questions during the interview. The in-depth interview was conducted as face-to-face as possible, and in situations where it was difficult to face-to-face due to the COVID-19, the interview was conducted through telephone and e-mail.

Interview questionnaires and survey question were sent via e-mail the day before the interview, and the interview and survey were conducted face-to-face on the same day. Taekwondo instructors in the U.S. were answered by primary email, and further questions were asked by phone and e-mail to compensate for the deficiencies. The purpose of the study was explained through the body of the e-mail in advance. Interview and survey were conducted only when the participants agreed. In order to supplement the limitations of the interview, a survey, a quantitative research method, was simultaneously conducted. The survey was designed to objectively identify job characteristics, job satisfaction, reward satisfaction, self-esteem, and career vision.

Table 2. Interview Questionnaires

\begin{tabular}{|l|l|}
\hline No. & Interview Questionnaires \\
\hline 1 & Changes and difficulties in Taekwondo gym and instructors due to the Covid-19 \\
\hline 2 & The Role of Taekwondo instructor and Self-esteem \\
\hline 3 & Taekwondo instructor's Job Classification and overall way of working \\
\hline 4 & Taekwondo instructor's Total rewards and work conditions \\
\hline
\end{tabular}




\begin{tabular}{|l|l|}
\hline 5 & Changes in Social Needs for the Role of Taekwondo gym \\
\hline Additional Question & Suggestions for Taekwondo development, including overcoming the Covid-19 era \\
\hline
\end{tabular}

※ Survey questions are attached as a separate file

\section{Data Analysis}

The interview results recorded the whole interview process, and the results were derived inductively by the interview results. In order to ensure objectivity when analyzing the interview results, interviews were conducted with multiple gym instructors, and the entire contents were verified by a judge of the Korean Taekwondo Association, who had more than ten years of experience as a master and instructor who did not participate in the interview. The survey results were used as supplementary data for the interview results by using the average value of the respondents on a Five-point rating scale.

\section{Research Ethics}

In order to comply with research ethics when conducting this study, the following standards were established and proceeded.

1. Prior to the interview, participants were informed of the purpose of the study, where to use it, and the sharing of future deliverables through e-mail and telephone conversations and confirmed whether they would voluntarily participate in the study.

2. During the interview, if the research participant felt uncomfortable or did not want to use the information, the interview was stopped, and the interview contents were not used.

3. For privacy purposes, all names were anonymous without informing other participants of their participation.

4. It was announced that the data collected for the study would not be used for any purpose other than the research.

5. In order to supplement the objectivity of the collected information due to the limitations of the interview parameters, the research results were reviewed by experts.

\section{Results}

This study directly cited the thoughts and problems that interviewees feels at work. And the results were described for each interview question.

\section{Changes in the Taekwondo industry due to Covid-19}

American and Korean Taekwondo instructors responded that they had the most challenging time since they started working in Taekwondo. Taekwondo has limitations for conducting online class because it has a lot of physical activity. And the Taekwondo gym was very sensitive to safety because there were many young students. In the United States, Taekwondo gyms were a means of after-school for children from low-income families. However, during the shutdown, most of them could not attend the Taekwondo classes. In the aftermath of COVID-19, a vicious cycle continued, including a sharp decrease in trainees, problems in renting a gym, and difficulties in paying instructor' wage. The polarization between Taekwondo gyms has also deepened due to the COVID-19. Only gyms with a certain amount of capital are still holding on. Recently, there is even a phenomenon of the rich grow richer, and the poor grow poorer, in which the surviving gyms absorb the nearby gyms having a hard time. In other words, the economically weak new gyms are experiencing more significant difficulties. 
In the early days of COVID19, the same vicious cycle was repeated in both the United States and Korea. However, the U.S. taekwondo industry recovered faster due to the spread of vaccines and the revitalization of online lessons.

"Taekwondo gym in the U.S. is more than just physical training and mental training. Taekwondo gym served as a care provider after 6 p.m. During last year's shutdown, there was a sense of crisis, but the local Taekwondo Association and the American Taekwondo Association quickly shared how to respond that situation: how to communicate with parents, how to manage safety and hygiene, etc. In addition, they shared online lessons and education methods through Zoom. This was worrisome at first, but surprisingly, the response from parents was good enough to maintain trainees through online lessons. Now that the vaccine has spread, the number of trainees has almost recovered from precorona." (Master 1, US)

On the other hand, Taekwondo industry in Korea is still not good. The vaccination is slow, but the bigger problem is that online lectures are difficult. There is a lack of support from the Taekwondo Association and it is difficult for individual gyms to prepare.

"The current corona situation is more difficult compared to the economic crisis in the past. The reason is that the health and safety of children are related. I asked parents to believe me when they didn't send children to the gym, but useless. There is no infrastructure and knowledge for online training and contents. Early last year, there was hope that it would end soon, but now I don't even have it, and I just think I have to endure it somehow." (Master 3, Korea)

\section{The Role and Self-esteem of Taekwondo instructor}

The self-esteem of a Taekwondo instructors were equally high in the United States and Korea. Of course, the nonKorean instructors had low self-esteem in Taekwondo itself, but the self-esteem as a Taekwondo instructor was as high as that of Korean instructors. The reason is that Taekwondo goes beyond the purpose of physical training and teaches essential virtues such as filial piety and honesty that children can grow up properly (McLaughlin 2020).

"I am very proud of spreading Korean traditional martial arts to the world. Taekwondo gym in the United States is recognized as a comprehensive cultural facility. It includes physical training, mental training, moral education, and even counseling. As a result, more roles are required. Instructors are also required to skill training, and there are situations in which they have to consult with parents and students or run liberal arts programs. It seems that society's expectations for Taekwondo are changing very fast. And we have to prepare for new roles." (Instructor 1, US)

"I didn't major in Taekwondo in college, and I have never been to Korea. However, I have trained at the small Taekwondo gym near my house since when I was 10 years old. I have a lot of pride as a Taekwondo instructor now. I am sometimes a coach and teacher for young students. Sometimes I can be their advisor and their friend. Without self-esteem, I would probably not able to truly perform my various roles." (Instructor 3, US)

I learned Taekwondo for a long time, and I'm plan to establish a Taekwondo gym in Mexico, my home. Taekwondo is a sport that benefits both the body and the mind. Above all, I am proud of helping children create the right values and think morally in their growing years. However, However, there was no master who offered me a long-term career vision. It is even harder to learn how to establish and operate a gym. Also, I hope there will be an opportunity to study the traditional spirit of Korea and the origins of Taekwondo." (Instructor 4, US)

"If you do not have pride in Taekwondo, you cannot play the role of an instructor properly. In fact, the reality is that the rewards or recognition are not so high. However, every day I think about how rewarding it is to teach my children the Taekwondo, and I try to set an example for them in words and actions." (Instructor 5, Korea)

Table 3. Self-esteem as a Taekwondo instructor (N=12, U.S and Korea)

\begin{tabular}{|l|l|l|}
\hline No. & Survey Question & Point (out of 5.0) \\
\hline 1 & I have pride as a Taekwondo Instructor. & 4.6 \\
\hline 2 & I am receiving social recognition as a Taekwondo Instructor. & 4.2 \\
\hline
\end{tabular}

$※$ Five-point rating scale: 1 point(Strongly Disagree) 5point(Strongly Agree) 


\section{The job classification and task operation of Taekwondo instructor}

Taekwondo gyms in the U.S. are clearly divided into roles and duties by instructor. However, Taekwondo gyms in Korea are not clearly divided into roles by instructor, and there are many additional tasks such as gym maintenance, cleaning and riding. So Korean instructors have a lot of overtime work.

"There are clearly divided roles of master, Korean instructor, and American instructor. The tasks are also differentiated by the length of experience, expertise and position rank. In general, instructors with less than three years of experience are in charge of administration and counseling, and senior instructors, more than 5 years of experience, are more focus on skill training and education. Cleaning, facility maintenance, and vehicle operation are handled by master directly or through an outsourcing service." (Instructor 2, US)

On the other hand, in Korea, it is common to designate a person in charge and handle tasks without distinction of roles and tasks. There is also a lot of overtime due to additional tasks.

"Regular working hours are 12 p.m. to 10 p.m., however there is a lot of overtime work before and after. In addition to Taekwondo instruction, there are too many additional tasks such as cleaning, equipment management, and event riding. There are separate responsibilities for some tasks, but when it is urgent, everyone must work together. In particular, the workload increases during test seasons." (Instructor 5, Korea)

"I am responsible for administrative work and student guidance and counseling, but I have never been taught exactly what to do and how to do it. If some new tasks are happened not clearly defined, I always look out for them, and whenever something happens, I'm afraid I'm going to do that task because I'm junior." (Instructor 6, Korea)

"I heard that the gyms of a certain size classify their duties by instructor and increase their role expertise. However, the reality is that most gyms are always short of hands. Riding is one of the biggest additional tasks, but the reality is that it has to be managed between instructors somehow. Recently, regulations requiring the use of a professional driver and an assistant teacher are also necessary. However, I am concerned that it can be a huge labor cost burden for a small taekwondo gym." (Master 4, Korea)

Table 4. Job classification and task operation

\begin{tabular}{|l|l|l|l|}
\hline No. & Survey Question & US (N=6) & Korea (N=6) \\
\hline 1 & I have clearly defined roles and duties. & 4.0 & 2.8 \\
\hline 2 & I do additional things beside of my fixed role. & 3.2 & 4.5 \\
\hline 3 & I often work overtime more than regular working hours. & 4.0 & 4.7 \\
\hline
\end{tabular}

$※$ Five-point rating scale: 1point(Strongly Disagree) 5point(Strongly Agree)

\section{The Total rewards and Working condition of Taekwondo Instructors}

Despite the high self-esteem, satisfaction with taekwondo instructors' total rewards and working condition in the U.S. and Korea was not very high. In the United States, social security support except for health insurance is weak and no one gives a career vision for a long term, so many instructors change gym or job in a short term. In Korea, overtime and weekend work is too much, but overtime allowance is not clearly paid. They also pointed out that the opportunities for vacation and self-development were insufficient.

Instructors in the United States receive only minimal health insurance, so they demanded improvements in insurance and severance pay systems for stable old age. On the other hand, overtime allowance is clearly paid per hour, and there are various career development opportunities supported by the U.S. Taekwondo Association..

"In Korea, the four major insurances are supported, but in the U.S. only the minimum health insurance is partially supported. Also we don't have a severance pay system. Instead, the overtime allowance is clear. Overtime is paid on an hourly basis, and weekend work also the same." (Instructor 1, US) 
"I don't think of being a Taekwondo instructor as a career for the rest of my life. Social security and severance pay is weak, and there is no long term vision and role model. For that reason, instructors want to another gym that offers better rewards or to establish their own taekwondo gym in their hometown." (Instructor 4, US)

"The state Taekwondo Association and the U.S. Taekwondo Association tried their best to respond to Corona situation. They provided career development programs to instructors and offered an online training infrastructure and manual. (Instructor 2, US)

On the other hand, in Korea, insurance-related legal standards are in place, but total rewards system was not well established such as additional allowances, career development opportunity and vacation. In other words, the system is in place, but instructor cannot use it freely. This situation is also related to the master's leadership and management style.

"We have to manage the gym with a limited number of people, so overtime and weekend work are understandable. However, there is no standard for overtime pay. As a result, masters set standards by themselves but there is a huge deviation from gym to gym. (Instructor 7, Korea)

"The four major insurances of the instructors are covered by law. However, some masters do not pay insurance premiums on an expedient basis. After all, total rewards and working conditions depend on the morality and attitude of the master, the gym owner." (Instructor 8, Korea)

"There are many things parents want from Taekwondo. New needs such as guidance for children, mental health management and counseling are emerging. However, the instructors do not have the expertise to satisfy such needs. The association provides seminars, but we have to pay a fee, and the content is not abundant. We need opportunities to develop knowledge and competencies that meet the needs of society, parents, and students." (Instructor 6, Korea)

Table 5. Total rewards and working condition

\begin{tabular}{|l|l|l|l|}
\hline No. & Survey Question & US $(\mathrm{N}=6)$ & Korea $(\mathrm{N}=6)$ \\
\hline 1 & I am satisfied with my total rewards. & 4.2 & 3.8 \\
\hline 2 & I'm on overtime and weekend pay. & 4.0 & 2.7 \\
\hline 3 & I have an opportunity to develop new competencies. & 3.8 & 2.5 \\
\hline
\end{tabular}

$※$ Five-point rating scale: 1point(Strongly Disagree) 5point(Strongly Agree)

\section{Discussion}

\section{Countermeasures for Taekwondo Industry in the Covid-19 Era}

Taekwondo gym in Korea still suffers from insufficient preparation for online Taekwondo lectures. Although the purpose and role of Taekwondo and the situation in response to the coronavirus may differ from country to country, there are differences in the response method after the coronavirus. In particular, the United States has succeeded in developing and spreading online teaching methods through cooperation between the association and many gyms (Han Hyejin 2020). The rapid introduction of online lessons in the U.S. was a great help to the maintenance of trainees. The supplementation of the contents allowed the overall quality of Taekwondo lessons to be improved. Although most of them mentioned the need for online classes during interviews with masters in Korea, all of them gave up, saying that home training or skill education would not be possible due to the many trainees residing in apartments. In addition, the masters responded that it was impossible to prepare an online facility and make content by themselves, and they are not even expecting the association's support.

The era of With Corona will come. If coronavirus spreads even during daily life, online lecture and selfquarantine should be done at any time. Preparation for online taekwondo education programs and facilities has become 
a must, not an option. It is urgent to benchmark online programs used in the U.S. by expanding investment and research at the association level and developing online content for Korean trainees (Baneuna 2020).

"Non-face-to-face, online taekwondo lessons can change the framework of gym-oriented taekwondo systems that have been in operation for decades. This crisis could turn into a good opportunity if the association boldly invests and prepares to access Korean taekwondo contents anywhere in the world." (Master 3, Korea)

\section{The way to Improve Taekwondo Instructor's Self-esteem}

The pride of Taekwondo masters was excellent in both Korea and the U.S. Nevertheless, some instructors experienced economic difficulties due to the coronavirus and felt skeptical about whether they should continue to teach Taekwondo as they lost their jobs or had to do two or three part-time jobs. The interview confirmed that if instructors can only focus on taekwondo training after receiving proper rewards for their work, they can maintain self-esteem. After all, total rewards and improvement of the working conditions are the basis for self-esteem.

"Taekwondo instructor is not an honorary position. It's a hard job, and we have to support our families. Coronavirus is causing a lot of unemployed of instructors. If there is no job, there is no pride. When we feel rewarded for our work, we can be proud and confident in front of our students." (Instructor 6, Korea)

\section{The way to Improve to Job system and Role Operations}

In order to operate with a small number of people, it may be effective for everyone to cooperate flexibly depending on the situation rather than the division of jobs. However, due to the top-down hierarchy, the workload of young instructors increases, and this imbalance sometimes reduces the fairness of the organization (Ra Hyunjung et al., 2008). The job classification and fair distribution of duties are also related to the master's philosophy of gym operation. It is also a vital role of the master to assign tasks according to the professional and experience of the instructors and to take care of the complaints of the instructors (Kim Hongseok 2007). If it is difficult to distinguish tasks, it is necessary to distribute roles and scope of tasks to reduce unpredictable events and increase responsibility and expertise in the given tasks. This is the role of the master and is something that can be improved immediately in consultation with the instructors.

"Recently, Taekwondo gym in Korea is also introducing a job classification system. This is similar to the U.S. position and promotion system. The job level shall be divided into training instructors, management instructors, senior instructors, etc., and each role and scope of work shall be set and operated like the U.S. gym. This has a purpose of distinguishing role, but it also has a motivational effect through step-by-step promotion." (Master 1, US) "More important than the job system is the master's operational know-how and management mind. Under the master, who understands the minds of instructors of various nationalities and races and is flexible in distributing tasks, there are few jobs changes of instructors. Some masters invest and encourage for instructors' growth. So, the master's knowhow and leadership in gym operation are important." (Instructor 2, US)

\section{The way to improve total rewards and working condition}

Improvement of total rewards is possible through the design of the personnel system like ordinary companies. As the role grows through the rank and promotion system, it is also necessary to pay more compensation, set new goals, and pay incentives when overachieving(Barrogo et al., 2014).

"After Corona, the polarization between gyms will intensify. To respond to this, managers need to change their management mindset. Like ordinary companies, flexible attendance and overtime pay should be provided and promotions and performance-based pay systems should be supplemented. A gym can be successful only when good instructors are maintained without changing jobs." (Instructor 5, Korea) 
In addition, in order to expand the vision of the instructor as a lifelong workplace and grow in the long term, career management must be supported, and new teaching techniques and opportunities to develop the capabilities that society wants(Kim Ji-young et al. 2020).

"The goal of Taekwondo is not to teach Taekwondo skills but to educate children properly. For this, instructors must be economically stable and socially recognized. The association and its masters should provide adequate compensation for living and provide opportunities for development and growth to be recognized by society." (Master 2, US)

\section{Conclusion}

This study confirmed that the Taekwondo instructors in the U.S. and Korea maintained high self-esteem as Taekwondo trainers and educators despite the challenging pandemic. In particular, their affection for the young trainees and the goal to help them grow properly was felt.

Nevertheless, there were points for improvement in terms of workload, rewards, career and skill development. Considering the size and operating characteristics of Taekwondo gyms, there are many opinions that it is difficult to define and divide the jobs and roles of each instructor clearly. There was an answer that even in the U.S. gyms, where job-oriented tasks are settled, it is difficult to classify the duties of each instructor. Nevertheless, the U.S. gyms are using external cleaning companies and professional drivers. Taekwondo gym in Korea needs to make efforts to reduce instructor's additional work other than student training and education.

In terms of total rewards, it is not easy to compare by country due to differences in insurance and salary standards. However, one thing confirmed is that it requires institutional standards and a culture in which masters take the lead to check and automatically pay overtime work.

Last but not least is education and career development for instructor. Ordinary companies provide reskilling and upskilling, leadership training, language studies, and even mental health through HRD programs. Of course, this is only possible in large companies. Therefore, the taekwondo associations should support instructors to learn skills and knowledge that meet social needs. This is related to the development of the instructors' competency and selfesteem and the overall development of the Taekwondo industry. In addition, online educational content and operation methods need to be prepared at the association level and distribute to each Taekwondo gym and instructor.

\section{Limitations}

The study had some limitations due to the coronavirus situation. As the social distancing level increased, many scheduled face-to-face interviews were canceled, allowing only half of the instructors were interviewed. Nevertheless, those who participated in the interview informed the reality of Taekwondo industry and provided sufficient opinions for the future of the instructors. In the future, In the future, I will conduct more interviews and surveys to find problems and solutions that instructors feel by country, race, gender and career.

\section{Acknowledgments}

Thank you, Han Jae-min, master of Seocho VTA Taekwondo, for helping interview, survey, and review for this research and telling about the vivid experience and improvement of the field. Also, I would like to thank master Heo Il-moo of Chicago and master Park Hee-won of North Carolina for helping research in the United States and conducting surveys on the U.S. masters. It was a difficult situation due to COVID-19, but they gave sincere advice to instructors to work and grow in a better environment. Lastly, I will think about the mindset of Taekwondo instructors that they mentioned during the interview and wrap up this research. 
"A Taekwondo instructor is not a person who teaches Taekwondo skills. The role of a true Taekwondo instructor is to create the proper values for children through Taekwondo and make the mindset and courage necessary to live in society." (Jae-min Han Master)

\section{References}

Baneuna (2020). A Study on Expectation and Counter Measures of Management Environment Change of Taekwondo gym after COVID-19. TAEKWONDO JOURNAL OF KUKKIWON, 11(4), 15-29. https://doi.org/10.24881/tjk.2020.11.4.15

Barrogo, N. J. K., Garcia, C. P., \& Lumba, L. M. (2014). Motivational Strategies Used By Sports Coaches: Implication To Sports Psychology. International Journal of sports, 7(3).

Han Heejin. "The U.S. Taekwondo Center is also a direct hit on 'Corona'... Quick response with Online training." Mookas Media, 19 March. 2020. https://mookas.com/news/17381

Hong Seok Kim (2007). The Study of Casual Relationship among Transformational,Transactional Leadership, SelfEfficacy and Job Performance of Assitant Leaders in Taekwoondo Places. JOURNAL OF Korean Society of Sports and Leisure studies, 31, 227-239. http://www.riss.kr/I410-ECN-0102-2009-690-008467796

Jung Taegyeom (2017) A Study of Taekwondo Instructors` Labor Environment Improvement. TAEKWONDO JOURNAL OF KUKKIWON, 8(3), 19-39. http://www.riss.kr/I410-ECN-0102-2018-600-000703263

Kang Seokjae (2012). A Study on the Values and Effects of the Global Sport of Taekwondo. Doctoral thesis, Graduate School of Physical Education, Kyung Hee University. http://www.riss.kr/link?id=T12860941

Kim Hyunsoo. “Taekwondo Center in Crisis Due to Coronavirus 19." Global News Paper, 7 April. 2020. http://www.globalnewspaper.co.kr/news/articleView.html?idxno=2461

Kim jiyoung, Kim Woocheol (2020). The Effect of Organizational Career Management Help on Turnover Intention: A Focus on the Mediating Role of Grit and Employee Engagement. Journal of Competency Development \& Learning, 15(3), 69-94. https://doi.org/10.21329/khrd.2020.15.3.69

Kim Kihong, Kim Dongkyu (2005). A Search for the Origin and Identity of Taekwondo. Journal of Korean Society for the Philosophy of Sport, Dance \& Martial Arts, 13(2), 89-104. https://doi.org/G704-001458.2005.13.2.003

Kim Setee (2007). A study on the Educational Values of Taekwondo. Master thesis, Graduate School of Education, Kyoun Gook University. http://www.riss.kr/KDMT1200700438

Kim Suhkyung, An Geuna (2020). Differences in the Perceptions of Taekwondo Instructors' Roles. The Korea Journal of Sport, 18(4), 47-55. http://dx.doi.org/10.46669/kss.2020.18.4.005

Korea Taekwondo Association. (2019). Taekwondo Center registration https://www.koreataekwondo.co.kr/e004/post/1488/e0042

Lee Heenyeong (2008). A result study about sports diplomacy through Taekwondo. Master thesis, Graduate School of Industry and Information Sciences, Kyung Hee University. http://www.riss.kr/KDMT1200861124 
Lim Sungho. "Taekwondo Masters said, Lock down for a month. Tell us how to survive." Yonhap News, 1 January. 2021. https://www.yna.co.kr/view/AKR20210101047000004?input=1195m

McLaughlin, A. (2020). The Physical and Physiological Demands of Taekwondo Training and International Competition. Doctoral thesis, Liverpool John Moores University. https://doi.org/10.24377/LJMU.t.00012840

Ministry of Culture, Sports and Tourism. (2018). Master Plan for the Promotion of Taekwondo https://www.mcst.go.kr/kor/s data/budget/budgetView.jsp?pSeq=827\&pMenuCD=0413000000

Park Sungun, Kim Nahye (2021) Taekwondo Masters' Daily Life and Worries Following the COVID-19 Pandemic. The Korean Journal of Physical Education, 60(1), 49-57. https://doi.org/10.23949/kjpe.2021.1.60.1.5

Ra Junghyun, Lee Songhak, Jeon Ikgi (2008). The Effect of Taekwondo Masters` Recognition of Organization Justice on Work Satisfaction, Organization Commitment, and Intention to transfer Occupation. Journal of sport and leisure studies, 33(1), 147-160. http://www.riss.kr/KINX2014180916

Song Kilsub (2004). Ways of Revitalizing Taekwondo Preparing for Strengthening Sports Exchanges Between the South and North Korea. Master thesis, Graduate School of Industry and Information Sciences, Kyung Hee University. http://www.riss.kr/KDMT1200452234

World Taekwondo Federation. (2017). WTF Taekwondo Peace Corps. WTF Taekwondo. P. 106. http://www.worldtaekwondo.org/wtnews/view.html?nid=137510\&mcd=C15 